\title{
Canaloplasty in the Treatment of Primary Open-Angle Glaucoma: Patient Selection and Perspectives
}

This article was published in the following Dove Press journal: Clinical Ophthalmology

\author{
Anna Byszewska (D) \\ Joanna Konopińska (iD ${ }^{2}$ \\ Aleksandra Kinga Kicińska (iD) \\ Zofia Mariak (iD ${ }^{2}$ \\ Marek Rękas (iD) \\ 'Department of Ophthalmology, Military \\ Institute of Medicine, Warsaw 04-I4I, \\ Poland; '2Department of Ophthalmology, \\ Medical University of Białystok, Białystok \\ 15-276, Poland
}

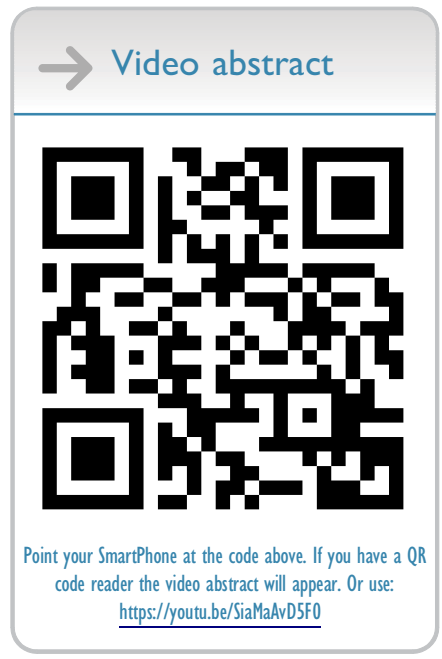

Correspondence: Anna Byszewska Department of Ophthalmology, Military Institute of Medicine, UI. Szaserów 128 ,

Warsaw 04-|4I, Poland

$\mathrm{Tel}+48-500-285-890$

Email ania.byszewska@gmail.com

\begin{abstract}
Canaloplasty is a surgical procedure that has undergone a number of developments since its introduction in 2005. Many thousands of canaloplasties have been performed around the world since then and is, by definition, a blebless procedure. It does not necessitate the use of any antifibrotic agents and results in safe and effective IOP reductions in patients with open-angle glaucoma (OAG) with minimal complications and no bleb-related adverse events. When considering the surgical management of patients with early and medium stages of the disease, canaloplasty can be considered as a first line option. This paper will overview the theoretical effectiveness of canal surgery, the fundamental aspects of aqueous outflow resistance with particular emphasis on the role of the trabecular meshwork, Schlemm's canal, and the collector channels, and the methods available for the clinical evaluation of the outflow pathways in relation to the ocular anatomy. Further, the paper will detail the surgical technique itself and how this has developed over time together with the clinical aspects that should be accounted for when selecting patients for this surgery.
\end{abstract}

Keywords: glaucoma, aqueous outflow, canaloplasty, minicanaloplasty, canaloplasty ab interno, ABiC, schlemm's canal, canaloplasty modification, canaloplasty patients selection, iTrack, canaloplasty qualification

\section{Introduction}

Surgery within Schlemm's canal is a technique that represents a dynamically developing field in the treatment of glaucoma. The iTrack ${ }^{\mathrm{TM}}$ microcatheter (Ellex Medical Pty Ltd, Adelaide, Australia) was first introduced to the glaucoma surgical armamentarium in 2005 with the introduction of the viscocanalostomy procedure in which Schlemm's canal undergoes viscodilatation. ${ }^{1}$ This technique has evolved with the addition of an intracanalicular tension suture to the canaloplasty procedure. This technique has been implemented for more than 14 years and has been demonstrated as being safe and effective. ${ }^{1,2}$ Canaloplasty has a superior safety profile when compared to many fistulizing procedures with the incidence of hypotony and hyperfiltration being low. ${ }^{2-6}$ As such the procedure is considered as being a technique that requires less intensive postoperative follow-up for patients whilst effectively managing IOP in suitable patients.

\section{The IOP Lowering Mechanism of Canaloplasty}

The standard technique comprises, in essence, two surgical procedures: nonpenetrating deep sclerectomy and viscocanalostomy/circumferential transluminal 
viscodilation with placement of a tension suture. ${ }^{7,8}$ In the case of canaloplasty, the internal wall of Schlemm's canal remains intact. ${ }^{2,9}$ These procedures involve the creation of a superficial scleral flap through excision of a small area of the sclera of about one third scleral thickness and deep scleral flap, leaving only a thin layer of tissue overlying the choroid. Further dissection leads to the creation of a TDM (trabeculo-Descemet membrane), through which aqueous humor perlocates from the anterior chamber into the intrascleral lake, with the potential of this flowing into the subconjunctival space. In canaloplasty, the superficial flap is usually closed in a water-tight manner to minimize any potential subconjunctival drainage, whilst in the case of deep sclerectomy, sutures may be loose or omitted entirely. ${ }^{9}$ During canaloplasty a flexible, fiber optic microcatheter is placed in Schlemm's canal and a viscoelastic is administered into its lumen. As the catheter is retracted, a 10-0 Prolene suture is simultaneously inserted into the canal and tied with a specific amount of tension that allows the inner wall of the canal to displace centrally. In this way, this surgical technique can permanently widen Schlemm's canal and the grade of trabecular meshwork extension may have an influence on IOP reduction and medication use. ${ }^{3,10}$

As such, Canaloplasty, represents an effective treatment modality that can enhance the physiological outflow mechanisms of the eye. The goal of the procedure is to restore, improve and preserve the natural aqueous outflow system and the essence of the procedure is to widen the lumen of Schlemm's canal and improve aqueous movement through the distal collector system. It can be that this technique may also facilitate drainage to the intrascleral lake and result in prolonged drainage of the aqueous humor in a mechanism that is not dissimilar to that seen with deep sclerectomy. ${ }^{9}$ This is done through the formation of an intrascleral decompression space that is made during the procedure which serves to produce a reservoir for the aqueous humour to reside and thus enables extended aqueous absorption within the space. ${ }^{8}$ The role of this intrascleral lake was previously investigated by Mermoud following the conduct of deep sclerectomy. ${ }^{11}$ This lake can be compared to the role the subconjunctival filtering bleb plays in trabeculectomy, which is a crucial one that results in the maintenance of continued IOP reduction. ${ }^{9}$ The creation of the intrascleral lake provides another drainage route into the intrascleral and suprachoroidal space. Descemet's membrane should remain intact and as such a semipermeable filtering membrane is created which provides a barrier between the anterior chamber and the decompression space that results in resistance to aqueous drainage thereby allowing effective intraocular pressure (IOP) control after the procedure and preventing potential hypotony. In the case of standard canaloplasty, it is unknown whether, and to what extent, the intrascleral lake influences pressure reduction within the eye. Some authors have suggested that a filtering bleb is also formed and that subconjunctival drainage occurs in $5-12 \%$ of patients following canaloplasty. ${ }^{4,5,7-13}$ Such blebs develop inadvertently either through seepage of aqueous through the gutters of the scleral flap or incomplete water-tight closure. However, to date, the resulting anatomy reported does not resemble typical filtering blebs. ${ }^{14}$

It is important that patient selection is considered carefully in order to optimize the likelihood of effective IOP lowering using this technique. The procedure changes the ocular anatomy that results in alterations to the physiological outflow system at three main sites of resistance: the trabecular meshwork (TM), Schlemm's canal and collector channels. ${ }^{4}$ In order to understand this procedure, some anatomical aspects must be considered.

\section{Aqueous Outflow Resistance}

Aqueous humor is formed by the ciliary epithelium and it passes from the posterior chamber to the anterior chamber through the pupil with it exiting at the site of the anterior chamber angle. The primary traditional pathway sees aqueous humor traveling through the trabecular meshwork and Schlemm's canal into the intrascleral venous plexus and episcleral veins and it is thought that this pathway is responsible for approximately $83-96 \%$ of aqueous flow. ${ }^{15,16,17}$ The secondary pathway, also known as the unconventional route, leads the aqueous via the ciliary body to the supraciliary and suprachoroidal space. From there it drains either through the sclera and orbital veins or through the choroid and vortex veins. The exact amount of aqueous that drains through this unconventional route remains uncertain with the literature indicating various percentages. ${ }^{19}$ Tamm et al have reported that the unconventional pathway could account for as much as $57 \%$ of the aqueous outflow. ${ }^{20}$ Maintenance of a healthy equilibrium between aqueous fluid production and its drainage results in IOPs that remain within an acceptable physiological range.

The traditional outflow pathway encounters resistance at the region between the anterior chamber and the external wall of Schlemm's canal. A significant cause of this resistance is seen at the level of the TM and inner wall of 
Schlemm's canal and results from fusion of adjacent trabecular columns due to trabecular endothelial cell loss, ${ }^{21-23}$ increased matrix metalloproteins in the juxtacanalicular $\mathrm{TM},{ }^{24,25}$ increased stiffness of the $\mathrm{TM},{ }^{26}$ and loss of vacuoles and micropores in the inner wall of Schlemm's canal. ${ }^{27-29}$ These changes and the resultant increase in resistance are hypothesized as being the cause of open-angle glaucoma. However, the actual cause and location of this pathologically enhanced resistance is still the subject of controversy.

The trabecular meshwork consists of three layers: an inner uveal part bordering with the anterior chamber, a middle corneoscleral layer and juxtacanalicular space adjacent to Schlemms canal inner wall. The site of the extracellular matrix seems to be the most important source of where trabecular resistance lies. The key responsible component recognized as being the cause of this resistance is the presence of glycosaminoglycans. These molecules are able to store large volumes of water and thus reduce the space available for the passage of fluid. ${ }^{30}$

\section{Schlemm's Canal}

Schlemm's canal has a unique histological anatomy that results in a reversed pressure gradient when compared to other vessels in the body - the pressure is higher in the lumen of the canal than the surrounding area. ${ }^{32}$ There is also a pressure gradient between the anterior chamber and Schlemm's canal. The basal to apical pressure gradient created allows for the creation of giant vacuoles in the endothelial cells lining the inner wall of Schlemm's canal, which in turn allows for the creation of intra and inter cellular micropores. These micropores enable the flow of aqueous from the anterior chamber to the episcleral veins. ${ }^{33,34}$ It has been shown that the inner endothelium wall of Schlemm's canal is vascular in origin, which differentiates it from cells located within the trabeculum..$^{35,36}$ Another unique characteristic of this structure is the presence of a basement membrane that lies under the inner wall endothelial cells that is discontinuous in nature, contains pores and is of variable thickness. ${ }^{37}$ Further the endothelium cells of the inner wall are connected via cytoplasmatic processes with juxtacanalicular cells (JC) and firmly attached to the endothelial cells lining the trabecular lamellae (TLC) ${ }^{38,39}$ This system of cytoplasmatic processes connects the endothelial cells of the inner wall of Schlemms canal with the JC and TLC and creates an architecture that can dynamically respond to fluctuations in IOP.
The tissue loading studies have shown that elevations in IOP cause correlating progressive distention of the IW endothelium outwards results in lumen occlusion which compromises the circumferential flow. ${ }^{32,40-44}$ In a report by Van Buskirk, almost one-third of the sections evaluated revealed collapse of Schlemm's canal. The collapse was defined as contact of the opposing walls for at least $75 \%$ of their length in cross section ${ }^{40}$ The apposition of the inner wall was also confirmed to be present in vivo at pressures of $20-25 \mathrm{mmHg}^{40}$

\section{Collector Channels}

The collector channels which, vary in number from 20 to 30 , arise from the external wall of Schlemm's canal and drain directly into the episcleral veins or indirectly via the intrascleral venous plexus. The outflow from Schlemm's wall occurs through ostia, which are present at various intervals and these openings are sometimes associated with septa, which prevent total occlusion. ${ }^{47,48}$ Some studies have demonstrated that the outflow pattern is uneven or "segmented" and relatively higher at specific parts in the canal ${ }^{47}$ called effective filtration areas (EFA), with increased flow occurring at channel openings (ostia). At any given time only some pathways are actively involved in percolation. The level of homogeneity seems to depend upon the level of IOP. ${ }^{49}$ However, these studies are not without limitation, since only a small amount of TM was analyzed in radial sections using electron microscopy. ${ }^{50}$ Battista et al demonstrated decreases in the outflow facility and a reduction in EFA to ostia vicinity using fluorescent trace and confocal microscopy scanning at different planes. These alterations were emphasized with increase in IOP and resulted from morphologic changes observed in the aqueous plexus (AP), a bovine equivalent of the human Schlemm's canal, such as collapse and TM/IW complex incomplete or complete herniation into the ostia. ${ }^{51,52}$ In this study, when IOP was at $30 \mathrm{mmHg}, 95 \%$ of the ostia were partially or completely obstructed. The CC ostia may be an important site of resistance affecting outflow pattern by most probably changing the pressure distribution in the canal lumen.

\section{Clinical Assessment of the Outflow Pathways}

It is important to assess the patency of distal outflow pathways when determining the effectiveness of such techniques. 
The reason for this is that canaloplasty targets sites that exhibit pathologically increased resistance with the aim to enhance the natural outflow pathway. It is therefore crucial to establish, whether the distal pathway remains patent. This can only be achieved however intraoperatively by provocative gonioscopy or through channelography. ${ }^{47,52-54}$

Static gonioscopy performed pre-operatively only enables visualization of the proximal part of outflow pathway- the uveal trabecular meshwork. Regurgitation of blood in the canal can be evoked by compression with a Goldman three-mirror lens. A much more useful and insightful is a provocative gonioscopy, where the pattern of blood reflux is assessed. It is performed intraoperatively in an eye with a previously induced hypotony following a paracentesis. ${ }^{47}$ The blood reflux is not provoked by a compression of the episcleral veins by the gonioscopic lens, but by the hypotony itself. Using this technique and assessing the amount of blood present in the angle, three filling patterns can be determined: no filling, incomplete filling, and complete filling. ${ }^{47}$ This technique provides information relating to the patency of Schlemm's canal and its connection to a patent distal system. Another method that can be employed to visualize the distal outflow pathway is by using dye that can be injected into the anterior chamber to visualize patent flow. ${ }^{52}$ Grieshaber et al described a new in-vivo procedure called channelography which involves the direct injection of fluorescein into Schlemm's canal using a microcatheter during the canaloplasty procedure. ${ }^{52}$ Episcleral outflow can then be assessed and graded according to the number of vessels that fill with dye in each quadrant.

Intraoperative provocative gonioscopy and channelography were evaluated in a study conducted by Grieshaber et al, where results of a multinomial regression model revealed that higher levels of IOP correlate with lower blood reflux rates independent of age. ${ }^{52}$ Furthermore, both episcleral egress and blood reflux were proven to be predictive factors of effective IOP reduction following canaloplasty. Preoperatively, the blood reflux pattern correlated inversely with IOP, which may help to explain the morphologic changes that are observed in SC in POAG eyes where increases in IOP result in Schlemm's canal lumen collapse, blood reflux decrease and episcleral egress reductions. Another way to analyze the anatomical status of the anterior chamber angle preoperatively and postoperatively is through ultrasound OCT imaging. iUltrasound (iScience Interventional, Inc.) uses a probe with a frequency of 80 $\mathrm{MHz}$ that enables visualization and measurement of
Schlemm's canal characteristics. ${ }^{54}$ Hann et al reported that the diameter of the canal and its distance from the limbus and anterior angle varies with axial length, race and pachymetry values. ${ }^{50}$ Collection and analysis of this information may therefore add more understanding to OAG pathology in the future and, from a practical point of view, enables the surgeon to assess location of the canal pre-operatively whilst also assisting intra-operatively. The measurements in a study published by Hann et al were taken in vivo, thus may reflect actual functional volume. ${ }^{50} \mathrm{~A}$ promising technique that could be used to provide more insight into the aqueous outflow pathway is aqueous angiography which to date has only been tested using enucleated eyes. ${ }^{53}$

\section{Patients Selection for Canaloplasty}

Canaloplasty is a technique that can be used as a treatment modality for patients diagnosed with early to mediumadvanced OAG when the progression of the disease is not rapid. ${ }^{4}$ Patients demonstrating IOP in the low twenties are expected to have a higher success rate after canaloplasty. Patients with higher IOPs (above $25-30 \mathrm{mmHg}$ ), as shown on animal model, are more likely to have an increased number of collapsed collector channels and as such are less likely to be patent even with alterations in the grade of tension of Schlemm's Canal or at least less responsive to the surgery with antiglaucoma medications being required during the initial postoperative period. ${ }^{51}$ Another important consideration when determining this technique as a treatment option for patients with OAG is that canaloplasty does not lower IOP below that of the episcleral veins. Therefore this technique is best aimed at those patients where a pressure of $13-15 \mathrm{mmHg}$ is targeted.

The most common intraoperative complication associated with canaloplasty is the inability of being able to pass the catheter through Schlemm's canal 360 degrees as a result of incorrect route of passage due anatomical anomalies. ${ }^{7}$ The success rate of canal cannulation ranges from $74 \%$ to $89.9 \%$ as reported in a number of different studies. ${ }^{4,5,8,55}$ Difficulties associated with intubation may occur in the event of unforeseen anomalies being present within Schlemm's canal in addition to prior laser procedures on the filtration angle (argon laser trabeculoplasty ALT) that have caused destruction of the trabecular meshwork structure and excessive scarring. ${ }^{56}$ Patients with angle anomalies, such as angle recession, anterior synechiae, glaucoma congenitum, should also be excluded. The treatment modality can be considered as an option for phakic patients without cataract as a standalone procedure 
since the incidence of hypotony is low thus minimizing the risk of postoperative cataract formation in cases of lenscorneal touch. ${ }^{57}$ A number of studies have reported the incidence of cataract formation over a 24 month postoperative period with the incidence ranging between 12.7 and $19.1 \%{ }^{58}$ In the case of the requirement for phacoemulsification following glaucoma surgery it is known that this results in a deterioration of filtering bleb functionality in penetrating surgery and as such can negatively affect the overall IOP control. Conversely, following canaloplasty phacoemulsification only has a slightly positive impact with there being an overall benefit to the IOP lowering effects. ${ }^{58-60}$

Canaloplasty may also be a safe and effective surgical option in patients with open-angle uveitic glaucoma, ${ }^{61,62}$ although it is not widely considered a first choice surgery due to the possibility of late suture erosion through TM associated with inflammation in these patients. ${ }^{61}$ This group of individuals is unique, with them being younger when compared to other OAG patients and their tendency to aggressive wound healing. The standard surgical procedure to treat uveitic glaucoma is trabeculectomy with mitomycin $\mathrm{C}$ or with the insertion of a glaucoma drainage device and both may lead to high rates of scarring and filtering bleb encapsulation. ${ }^{63,64}$ Also long-standing hypotony and hypotony maculopathy, as well as cataract progression are more common postoperative complications in this sub-set of patients when compared to standard POAG patients. ${ }^{65}$ Provided that the inflammation is well controlled at the time of surgery, pre-existing uveitis is less indicative of trabeculectomy failure when compared with postoperative intraocular inflammation. ${ }^{65}$ Canaloplasty, on the other hand, allows to avoid the aforementioned complications in most cases. Again, careful consideration of patients is vital when predicting potential success of the procedure, which means the uveitis must be under control and patients with anterior synechiae must be excluded.

It is important to note that canaloplasty may be a secondary procedure, performed on patients who have previously undergone trabeculectomy or tube surgery. It can be performed in patients with a previously failed trabeculectomy when gonioscopic examination reveals an intact Schlemm's canal. ${ }^{66,67}$ Full canaloplasty with suture placement cannot be achieved in eyes, in which a portion of Schlemm's canal is excised together with the trabecular meshwork. In some cases, however, the tissue is excised anteriorly to the angle structures and then the procedure can be performed. Modern trabeculectomy is rather a sclerokeratectomy, which leaves the canal intact. ${ }^{68}$ Brusini et al revealed that secondary canaloplasty may be successful with mean IOP reductions of $15.9 \mathrm{~mm} \mathrm{Hg}$ $(49.4 \%)$ at 2 years, being reported with starting IOP levels ranging from 25 to $48 \mathrm{mmHg} .{ }^{66}$ What is more, canaloplasty is not always contraindicated in cases of previous filtration surgery and regionally disrupted Schlemm's canal, as suggested by Xin et al. ${ }^{69}$ When complete circumnavigation is not possible due to canal abnormalities in the region of previous surgery, a novel trocar assisted cannulation technique can be used. This group reported that at 12 months the average IOP decreased significantly when compared to baseline values and that there were no significant differences between subjects who had canaloplasty performed as a primary procedure compared to those who had undergone previous filtration surgery with canaloplasty as a secondary procedure.

\section{Canaloplasty and Modifications to the Procedure}

The standard canaloplasty technique involves passage of an illuminated microcatheter through 360 degrees of Schlemm's canal, leaving high viscosity sodium hyaluronate (Healon GV) in its lumen and placing a Prolene suture to provide tension to the canal walls and adjacent trabeculum inward. ${ }^{2}$ This technique will be described in full later in this paper. These procedures are continuously being modified in order to simplify the surgical technique since non-penetrating anti-glaucoma operations are technically challenging. ${ }^{69-71}$ Nowadays, it can be said, that canaloplasty is not a single procedure, but more of a group of procedures. All of these are conducted within Schlemm's canal however, they differ in their methodology and how it is accessed. The canal can be accessed either ab interno or ab externo. The procedure can be performed with or without viscodialation, and finally, a tensioning suture may be placed as part of the technique or omitted entirely. A summary of the different techniques of cannulation is presented in Table 1 .

\section{Standard Canaloplasty - Description of Surgical Technique}

Canaloplasty evolved from Stegmann viscocanalostomy with the incorporation of 360 degree catheterization. ${ }^{72}$ A fornix-based conjunctival flap is dissected in the upper quadrant to expose the sclera. A $5.0 \times 5.0 \mathrm{~mm}$ scleral superficial flap, parabolic in shape, is dissected anteriorly 
Table I Canaloplasty and Its Modifications. Summary of the Unique Features of Each Type of Procedure

\begin{tabular}{|c|c|c|c|c|c|c|}
\hline Canaloplasty Features: & $\begin{array}{l}\text { Classic } \\
\text { Canaloplasty }\end{array}$ & $\begin{array}{l}\text { Cathetherless } \\
\text { Canaloplasty }\end{array}$ & $\begin{array}{l}\text { Canaloplasty } \\
\text { with } \\
\text { Glaucolight } \\
\text { catheter }\end{array}$ & $\begin{array}{l}\text { Canaloplasty } \\
\text { with } \\
\text { Suprachoroidal } \\
\text { Drainage }\end{array}$ & Minicanaloplasty & ABiC \\
\hline Characteristic feature & & & $\begin{array}{l}\text { Glaucolight } \\
\text { catheter }\end{array}$ & $\begin{array}{l}\text { Suprachoroidal } \\
\text { drainage }\end{array}$ & $\begin{array}{l}\text { Smaller } \\
\text { sclerectomy }\end{array}$ & Least invasive \\
\hline $\begin{array}{l}\text { Approach to Schlemm's } \\
\text { canal }\end{array}$ & ab externo & ab externo & ab externo & ab externo & $a b$ externo & $a b$ interno \\
\hline Catheter type & iTrack & prolene 6-0 & Glaucolight & iTrack & iTrack & iTrack \\
\hline \multirow[t]{2}{*}{ Superficial flap } & $5 \times 5 \mathrm{~mm}$ & $5 \times 5 \mathrm{~mm}$ & $5 \times 5 \mathrm{~mm}$ & $4 \times 4,5 \mathrm{~mm}$ & $4 \times 1 \mathrm{~mm}$ & \multirow[t]{2}{*}{$x$} \\
\hline & parabolic & parabolic & Parabolic & Parabolic & rectangular & \\
\hline Deep scleral flap & $4,5 \times 4 \mathrm{~mm}$ & $4,5 \times 4 \mathrm{~mm}$ & $4,5 \times 4 \mathrm{~mm}$ & $3,5 \times 4 \mathrm{~mm}$ & $|x|$ & $x$ \\
\hline Viscodialation & v & $x$ & $x$ & v & v & v \\
\hline Tensioning suture left in S.C. & $v$ & v & v & v & v & $x$ \\
\hline Intrascleral lake & v & v & v & v & $x$ & $x$ \\
\hline Suturing conjunctiva & $v$ & v & $v$ & v & $x$ & $x$ \\
\hline
\end{tabular}

Notes: v-present; $x$-not present.

Abbreviation: S.C., Schlemm's canal.

into the clear cornea using a method previously described by Bellucci and Morseli. ${ }^{73}$ (Figure 1A) Afterwards, the deep scleral flap $(4,5 \times 4 \times 0,75 \mathrm{~mm}$ in diameter $)$ and TDM (Trabeculo Descemetic Membrane) are dissected (Figure 1B) and a microcatheter (iTrack ${ }^{\mathrm{TM}}$, Ellex Medical Pty Ltd, Adelaide, Australia) is placed in the Schlemm's canal and advanced 360 degrees within the canal. Once the catheterization of the canal is complete, (Figure 1C), the distal tip is exposed, and a $10-0$ polypropylene suture is tied to the distal tip, (Figure 1D). The microcatheter is then withdrawn, and the suture is pulled into the canal. The surgeon observes the location of the beacon tip through the sclera and injects viscoelastic every two clock hours. As the microcatheter appears at the other ostium of the canal, it is separated from the suture. A loop is created, encircling the inner wall of Schlemm's canal, (Figure 1E). Then, the suture loop is tightened to distend the trabecular meshwork inward. The sutures are placed under tension, and locking knots are added. The incidence of blood reflux when tensioning the suture is a sign of permeability of the distant outflow pathways and seems to be a positive prognostic factor to the patency of the system and postoperative IOP reduction. ${ }^{74}$ The deep scleral flap is excised and the superficial flap is sutured tightly in order to prevent leakage and subsequent bleb formation, which is perceived in this procedure as a complication. ${ }^{14}$ (Figure 1F). The conjunctiva is sutured down over the limbus with one interrupted 8-0 monofilament vicryl suture. Cauterization in the surgical area should be avoided wherever possible, in order to preserve potential outflow pathways.

\section{Cathetherless Canaloplasty}

An interesting modification of canaloplasty is the intubation of Schlemm's canal using a traditional ab externo approach and a 6-0 prolene suture. This technique was introduced as a method for $360^{\circ}$ trabeculotomy by Beck et al in 1995 in the treatment of primary congenital glaucoma. ${ }^{75}$ In 2010 Scharioth and Kodomskoi independently described the procedure as a surgical method for the treatment of OAG. ${ }^{76,77}$ After proper tissue dissection when performing deep sclerectomy, Schlemm's canal was accessed and a viscoelastic substance was injected into the ostia in order to distend the lumen of Schlemm's canal and enable the introduction of a prolene- 6-0 suture into the canal. The suture probe was blunt and slightly curved or formed in a double spiral. After successful cannulation, once the suture probe was at the other ostium, the 10-0 polypropylene suture was tightened to it and introduced in the canal during withdrawal of the stiff suture probe. In the case when intubation was not possible, 


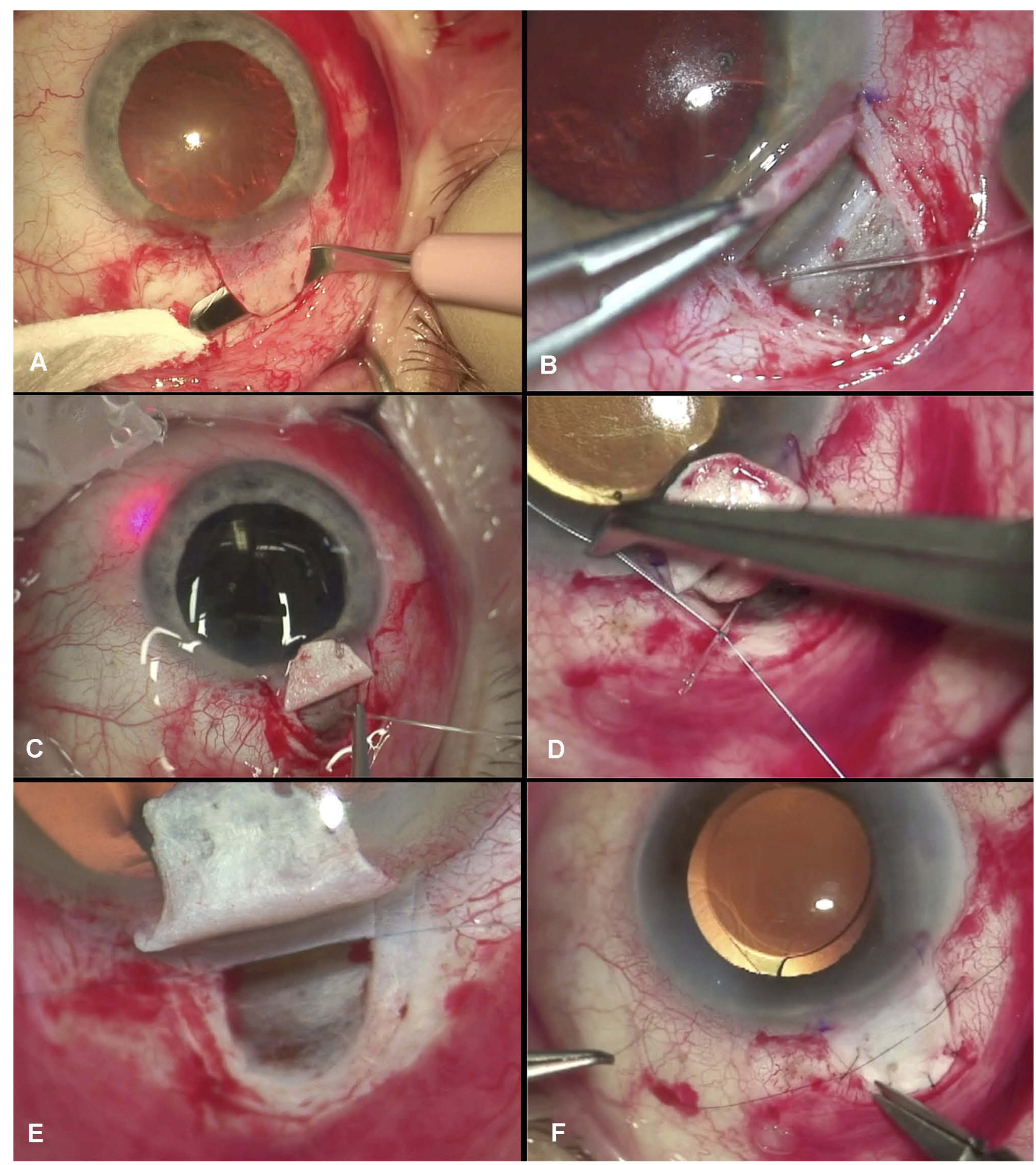

Figure I The surgical technique of canaloplasty. (A) Peritomy and dissection of the superficial scleral flap. (B) Creation of a trabeculo-descemetic membrane and visualization of the scleral spur and Schlemm's canal. The insertion of the iTrack catheter in the ostium of the canal. (C) After successful catheterization of the canal the iTrack catheter is seen at both ostia. (D) Bonding the Prolene suture to the distal end of the iTrack catheter. (E) Placing Prolene 10-0 suture in the canal with simultaneous viscodilatation. (F) Watertight suturing of the superficial scleral flap.

Notes: Copyright @2016. Okulistyka: Kwartalnik Medyczny. Byszewska A, Rudowicz ], Lewczuk K, Rękas M. Nowości w technikach chirurgicznych kanaloplastyki. [Update on Surgical Techniques in Canaloplasty]. 2016;3:14-19. Polish. ${ }^{91}$

the canal was approached from the opposite side. Afterward, a deep scleral flap was excised, and the viscoelastic was administered under the superficial flap to prevent bleeding and delay the fibrosis, which is the standard procedure for sclerectomy. The superficial flap was sutured watertight. 
This method has one very important consideration as financially it is a more affordable procedure than canaloplasty with the requirement of a traditional disposable iTrack set. When cannulation of Schlemm's canal is successful superior intraocular pressure-lowering effects are achieved when compared to classic deep sclerectomy in addition to a reduced postoperative burden. When problems are encountered the procedure can be converted to that of classic deep sclerectomy or trabeculectomy thus meaning other options are open in the case of failure. However, it is a very difficult and time consuming technique with a relatively high risk of mispassage of the 6-0 polypropylene suture into the anterior chamber or suprachoroidal space. ${ }^{78}$

Haus et al performed canaloplasty with suprachoroidal drainage using a standard 6/0 polypropylene suture, which was twisted in a special manner so that it created a double helix with a small loop at its end (similar solution to previously presented by Kodomskoi). ${ }^{79,80}$ The authors reported that the blunt loop ensures an atraumatic probing of Schlemm's canal, whereas the configuration as a double helix provides a good rigidity of the suture. A superficial and deep scleral flap was dissected so that the choroid was uncovered completely. A Descemet's window was created while avoiding perforation of Descemet's membrane. Schlemm's canal was unroofed with forceps and the trabecular meshwork was peeled away. Before initiation of probing, the orifices of Schlemm's canal were covered with a hyaluronic acid and the $360^{\circ}$ suture probing was then performed. The deeper scleral flap was resected so that the choroid was uncovered completely and the 10-0 prolene was tightened to the probe and introduced into the canal where the probe was pulled backward. The 10-0 suture was then left in the canal, under tension (a locking knot was added in the area of the unroofed Schlemm's canal). A depot of hyaluronic acid was injected into the suprachoroidal space and the superficial scleral flap was sewed watertight to prevent the development of a filtering bleb. The authors reported 12-month results on 74 eyes, of which 57 were successfully intubated. Seventeen eyes could not be intubated due to adhesions in the canal, of whom 5 were successfully intubated using a standard canaloplasty catheter (iTrack). Mean IOP within the group who underwent successful suture probe canaloplasty decreased by $39.2 \%$ (from $19.8 \pm 4.3 \mathrm{mmHg}$ with $3.4 \pm$ 0.7 anti-glaucoma drops to $12.0 \pm 1.9 \mathrm{mmHg}$ with $0.6 \pm$ 0.9 eye drops). The authors also reported that in the case of insufficient IOP levels being reached, a $360^{\circ}$ suture trabeculotomy during the follow-up phase can be carried out. ${ }^{81}$ No serious or sight-threatening complications occurred. Authors emphasized that in cases where probing with the suture fails, there still remains the option to use a conventional microcatheter or switch to sclerectomy with collagen sheet implantation in the suprachoroidal space. Again, the cost-effectiveness of this method seems to be of great importance.

\section{Canaloplasty with Glaucolight (D.O.R.C. Dutch Ophthalmic Research Center, Zuidland, the Netherlands)}

This alternative to canaloplasty was proposed by Scharioth, whose research resulted in the design and production of the alternative canaloplasty set. ${ }^{78,82}$ The probe itself has a smaller diameter $(150 \mu \mathrm{m} / 40 \mathrm{G})$ with a bluntended tip and is more flexible than the standard. It consists of an integrated, sterile LED light source for illumination and visualization of the fiber tip during cannulation which is a single-use device. It is not connected to an external light source, unlike the iTrack and most importantly is not equipped with an Ophthalmic viscosurgical device (OVD). The viscoelastic material is only injected in the ostia of Schlemm's canal in order to enable the cannulation, without viscodilating the whole circumference. Once the probe appears at the opposite ostium of the canal, a 10-0 polypropylene suture is tied to the distal tip and the microcatheter withdrawn, pulling the suture into the canal. Similarly to standard canaloplasty, a loop is created, encircling the inner wall of Schlemm's canal. The deep scleral flap is excised, whereas superficial is sutured in a watertight manner.

In a recently published paper, Vastarbis et al reported that the efficacy of canaloplasty either with the standard iTrack set or with the Glaucolight is similar. ${ }^{83}$ This conclusion was derived from a retrospective analysis of 54 eyes that underwent iTrack canaloplasty with a comparison against 56 eyes that underwent Glaucolight canaloplasty with assessment at 12 months post-op. The authors of this comparison emphasize that the risk of Descemet membrane detachment is lower with Glaucolight assisted canaloplasty, which is said to be as a result of viscodilatation. ${ }^{78}$

\section{Canaloplasty with Suprachoroidal Drainage (SCD)}

This modification was presented in 2016 by Szurman et al and the main difference of this variation is the manner in 
which the deep scleral flap dissection is conducted. ${ }^{80}$ Canaloplasty with suprachoroidal drainage involves the excision of a full-thickness block of the sclera until the choroid is visualized. The authors stress the specific feature of the sclera, that it is attached to the choroid at only two anatomical sites, at the scleral spur and optic disc, and that the suprachoroidal access facilitates the most challenging step of the canaloplasty surgery: the localization of Schlemm's canal. As soon as Schlemm's canal is located, it can be unroofed and then probed by a flexible microcatheter or intubated with a prolene suture and distended with viscoelastic. After excision of the deep flap, the superficial flap is sealed watertight so that no filtering bleb develops intentionally. The aqueous humor from the Schlemm's canal does not drain into an intrascleral filtering space but directly to the choroid - into the suprachoroidal space. ${ }^{80}$

Annual follow up on a large group of 417 patients were published in $2016 .^{70}$ In this paper, standard canaloplasty was compared to Canaloplasty with suprachoroidal drainage (retrospective analysis of 180 vs 237 operated eyes). Mean IOP reduction was higher following canaloplasty involving suprachoroidal drainage (35.9\%), from baseline $20.9 \pm 3.5$ $\mathrm{mmHg}$ to $13.1 \pm 2.5 \mathrm{mmHg}$ than after conventional canaloplasty (31.2\%) from baseline $20.8 \pm 3.6 \mathrm{mmHg}$ to $14.0 \pm 2.6$ $\mathrm{mmHg}$ ). The number of IOP-lowering medications prescribed reduced from $3.5 \pm 0.9$ to $0.7 \pm 1.0$ after SCD and from $3.4 \pm 0.9$ to $0.8 \pm 0.9$ after conventional canaloplasty and did not differ between the groups. It should be noted, however, that more patients were medication-free 1 year following SCD canaloplasty $56.9 \%$ vs $45.4 \%$ in the conventional canaloplasty group. No serious complications were reported in either group and the authors concluded that canaloplasty with suprachoroidal drainage achieves a higher IOP reduction than standard canaloplasty with fewer patients requiring medications one year post-op.

\section{Minicanaloplasty}

In this method, proposed by the author (M.R.), the size of both the scleral flaps are modified. ${ }^{84,85,86}$ The superficial flap dimension is $4.0 \times 1.5 \mathrm{~mm}$, and the deep flap $1.0 \times 1.0 \mathrm{~mm}$ (Figure 2A). After accessing Schlemm's canal classically using an ab-externo technique, the ostium is intubated with the iTrack and viscoelastic is injected through every $2 \mathrm{hrs}$ of the canal's circumference during withdrawal of the catheter (Figure 2B-D). A tensioning suture is pulled inward, the same way as in standard canaloplasty, (Figure 2E). The only other difference is that in minicanaloplasty the deep scleral flap is not excised and no intrascleral lake or trabeculo-descemet membrane is dissected. The relatively small superficial flap eliminates the requirement for suturing it only necessitating the closure of the conjunctival flap." (Figure 2F).

The main advantages of this methodology are shorter times for the surgery, less trauma to the tissue and no need for suturing the sclera. However, no intra-scleral lake is created, which results in fewer alternatives for aqueous outflow.

\section{Canaloplasty Ab Interno (ABiC)}

Ab-interno canaloplasty is an innovative mini-invasive method, different from the methodologies presented thus far. Introduced by Gallardo in 2015, it is based on an ab-interno approach to Schlemm's canal through a self-sealing temporal $1.8 \mathrm{~mm}$ clear corneal incision. ${ }^{87}$ The canal is accessed under gonioscopic view and because of this technique's tissuesparing potential, it is regarded as Minimally Invasive Glaucoma Surgery (MIGS). The procedure is performed in the nasal part of the irido-corneal angle and the canal is opened through an incision. The iTrack microcatheter enters the canal and is threaded through its whole circumference under the direct visualization of an illuminated beacon tip. After completing the cannulation, the catheter is withdrawn and viscoelastic is injected in a standard manner. The Prolene suture placement is omitted in this method.

The main advantage of $\mathrm{ABiC}$ is its minimally invasive nature. ${ }^{87}$ The conjunctival and scleral tissues remain intact, nonetheless, the canal is dilated, the collector channels opened, and the trabeculum distended. In the case of an unsatisfactory hypotensive effect, the eye remains naive to standard glaucoma filtering procedures and the technique itself has an exemplary high safety profile. ${ }^{87}$

\section{Clinical Results}

Recently, results from 75 eyes at one year post op were reported. ${ }^{87}$ The mean baseline IOP was $20.4 \pm 4.7 \mathrm{mmHg}$ with average medication usage being $2.8 \pm 0.9$. This lowered to 13.3 $\pm 1.9 \mathrm{mmHg}(\mathrm{n}=73)$ on $1.1 \pm 1.1$ medications at one year. This equates to a mean IOP decrease of $32.3 \%$ and a reduction of greater than $20 \%$ in $84.9 \%$ of eyes. All eyes in the study achieved an IOP lower than $18 \mathrm{mmHg}$ at 12 months post op. The mean number of medications decreased by $60.0 \%$. Overall, $40 \%$ of eyes were medication-free at 12 months. $\mathrm{ABiC}$ combined with cataract achieved slightly better results than the standalone procedure. No severe adverse effects occurred. Additionally, ABiC induces no astigmatism. Summarizing, this procedure could be considered for patients 


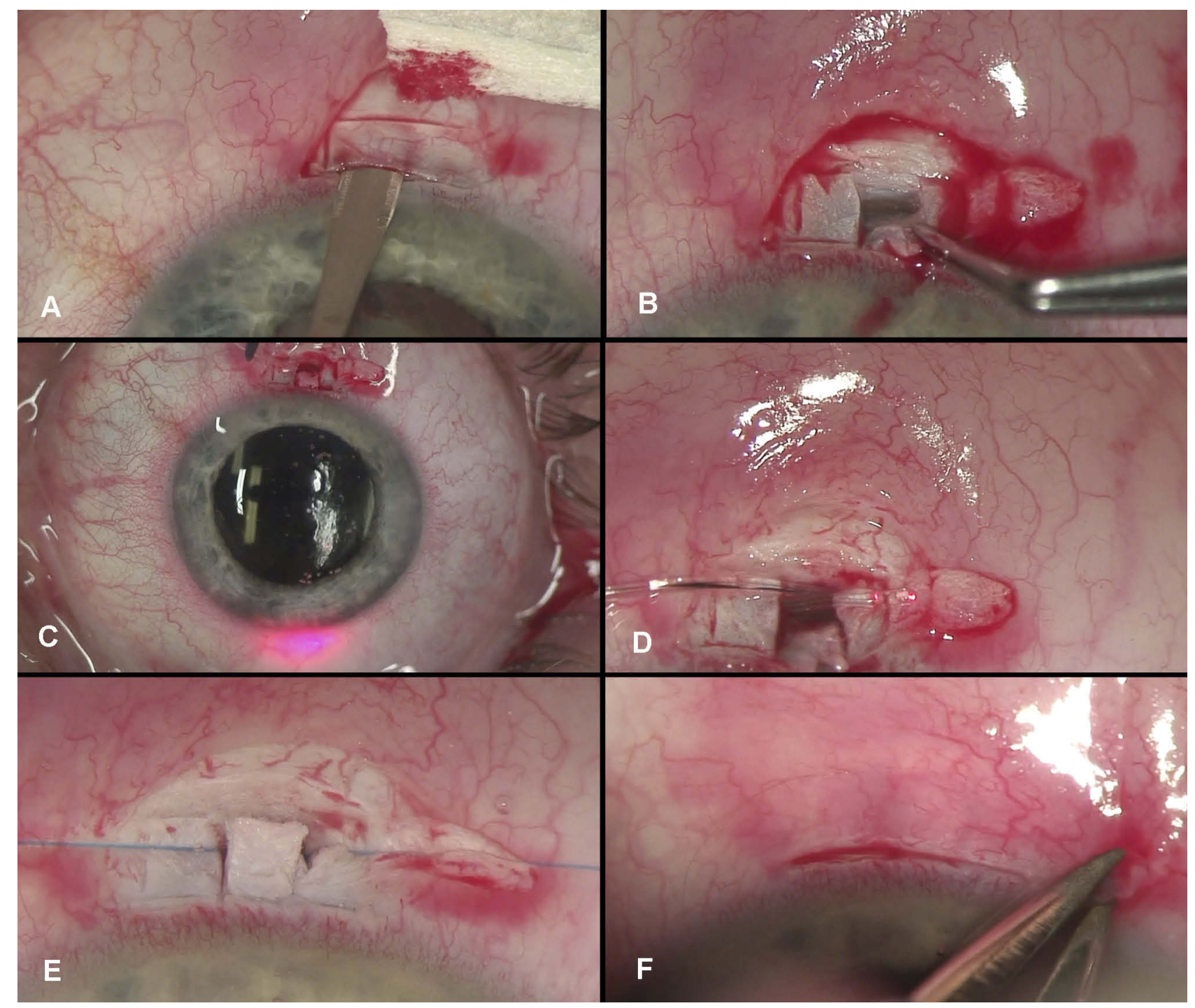

Figure 2 The surgical technique of minicanaloplasty. (A) Peritomy and dissection of the superficial scleral flap (4xImm). (B) Dissection of a small deep scleral flap ( IxImm) in order to access Schlemm's canal. (C) The illuminated tip enables transscleral visualization of the catheter during $360^{\circ}$ cannulation. (D) Following successful catheterization of the canal, the iTrack catheter is seen at both ostia. (E) The viscodilatation and placement of the Prolene 10-0 suture under tension in the Schlemm's canal are completed. (F) Closure of the conjunctiva with diathermy or with a single Vicryl 8-0 suture.

Notes: Copyright (2016. Okulistyka: Kwartalnik Medyczny. Byszewska A, Rudowicz J, Lewczuk K, Rękas M. Nowości w technikach chirurgicznych kanaloplastyki. [Update on Surgical Techniques in Canaloplasty]. 2016;3:14-19. Polish. ${ }^{91}$

with modest IOP targets, with or without cataract. ABiC may be a reasonable and minimally invasive treatment modality for those patients where reductions in medication load are sought in order to spare the conjunctiva for future filtration surgery if required.

New trends in the way in which Schlemm's canal surgery is conducted aim at minimizing trauma to the ocular structures. Moreover, the last two methods presented within this paper require no creation of an intrascleral lake, thereby eliminating any access to the suprachoroidal space and uveoscleral pathway. Similarly, no intrascleral lake is created in a more recent novel surgical procedure introduced by Grieshaber et al, named flap-sparing canaloplasty. ${ }^{88}$ After excision of the conjunctiva, no superficial and deep scleral flaps are dissected, but access to Schlemms canal is obtained through successive "scratching" down by implementation of radial incisions until Schlemm's canal is opened. After gaining access to Schlemms canal, Grieshaber proposed the implantation of Stegmann Canal Expanders followed by watertight closure of the sclera. ${ }^{88}$

It is not known yet whether the intrascleral lake plays a role in the efficacy of post canaloplasty IOP reduction. 
Certainly, no uveoscleral outflow could be a potential disadvantage of these techniques when considering the potential IOP reduction.

Further studies are required to provide more detailed insight into these different techniques. It is important to gain a better understanding of the impact these different methodologies have on IOP reduction and in determining whether ab externo techniques result in superior IOP reductions. This information will assist surgeons to better select optimum surgical techniques on a per patient basis as determined by disease and IOP status. Clinical results will give the answers.

The authors of this study are currently conducting a prospective, randomized clinical trial in which three canaloplasty techniques, including minicanaloplasty, are being assessed. The main goal of this study is to investigate the effect the intrascleral lake has on the IOP lowering effect observed in canaloplasty. The trial is registered at www.clinicaltrials.gov; Identifier NCT02908633.

In conclusion, canaloplasty offers an option for surgical intervention in the treatment of OAG at an earlier stage than traditionally seen with trabeculectomy. It can be readily applied in patients with a high risk of hypotony, scarring and inflammation. The procedure itself exhibits a favorable safety profile with there being relatively low interference within the eye's structure. As such the technique results in quicker convalescence and a lesser burden to the patients, ${ }^{89}$ in addition to requiring less intensive follow up by the physician. Patients experience less discomfort after canaloplasty when compared to traditional trabeculectomy and fewer unscheduled visits are needed, as there is no need for maintenance of the filtration bleb. ${ }^{90}$

\section{Acknowledgment}

Authors would like to acknowledge Ora Europe Ltd for their medical writing support in the manuscript.

\section{Disclosure}

The authors report no conflicts of interest in this work.

\section{References}

1. Cameron B, Field M, Ball SKJ. Circumferential Flexile, viscodilation of Schlemm's canal with a glaucoma, microcannula during nonpenetrating surgery. Digit J Ophthalmol. 2006;12(1).

2. Lewis RA, von Wolff $\mathrm{K}$, Tetz M, et al. Canaloplasty: circumferential viscodilation and tensioning of Schlemm's canal using a flexible microcatheter for the treatment of open-angle glaucoma in adults: interim clinical study analysis. J Cataract Refract Surg. 2007;33 (7):1217-1226. doi:10.1016/j.jcrs.2007.03.051
3. Lewis RA, von Wolff K, Tetz M, et al. Canaloplasty: circumferential viscodilation and tensioning of Schlemm canal using a flexible microcatheter for the treatment of open-angle glaucoma in adults: two-year interim clinical study results. J Cataract Refract Surg. 2009;35(5):814-824. doi:10.1016/j.jcrs.2009.01.010

4. Lewis RA, Von Wolff K, Tetz M, et al. Canaloplasty: three-year results of circumferential viscodilation and tensioning of Schlemm canal using a microcatheter to treat open-angle glaucoma. $J$ Cataract Refract Surg. 2011;37(4):682-690. doi:10.1016/j.jcrs.2010.10.055

5. Brusini P, Caramello G, Benedetti S, Tosoni C. Canaloplasty in open-angle glaucoma: mid-term results from a multicenter study. J Glaucoma. 2014. doi:10.1097/IJG.0000000000000103

6. Brusini P, Caramello G, Benedetti S, Tosoni C. Canaloplasty in open-angle glaucoma. J Glaucoma. 2016;25(5):403-407. doi:10.1097/ IJG.0000000000000103

7. Grieshaber MC, Pienaar A, Olivier J, Stegmann R. Canaloplasty for primary open-angle glaucoma: long-term outcome. Br J Ophthalmol. 2010;94(11):1478-1482. doi:10.1136/bjo.2009.163170

8. Bull H, von Wolff K, Körber N, Tetz M. Three-year canaloplasty outcomes for the treatment of open-angle glaucoma: European study results. Graefes Arch Clin Exp Ophthalmol. 2011;249(10):1537-1545. doi:10.1007/s00417-011-1728-3

9. Roy S, Mermoud A. How does nonpenetrating surgery work? $J \mathrm{Fr}$ Ophtalmol. 2006;29(10):1167-1174. doi:10.1016/S0181-5512(06)73 916-X

10. Brandao LM, Schötzau A, Grieshaber MC. Suture distension of Schlemm's canal in canaloplasty : an anterior segment imaging study. J Ophthalmol. 2015;2015:457605. doi:10.1155/2015/457605

11. Chiou AG-Y, Mermoud A, Underdahl JP, Schnyder CC. An ultrasound biomicroscopic study of eyes after deep sclerectomy with collagen implant. Ophthalmology. 1998;105(4):746-750. doi:10.1016/S0161-6420 (98)94033-7

12. Harvey BJ, Khaimi MA. A review of canaloplasty. Saudi J Ophthalmol. 2011;25(4):329-336. doi:10.1016/j.sjopt.2011.08.003

13. Klink J, Schmitz B, Lieb WE, et al. Filtering bleb function after clear cornea phacoemulsification: a prospective study. $\mathrm{Br} J$ Ophthalmol. 2005;89(5):597-601. doi:10.1136/bjo.2004.041988

14. Klink T, Panidou E, Kanzow-Terai B, Klink J, Schlunck G, Grehn FJ. Are there filtering blebs after canaloplasty? J Glaucoma. 2012;21 (2):89-94. doi:10.1097/IJG.0b013e3182027905

15. Jocson VL, Sears ML. Experimental Aqueous Perfusion in Enucleated Human Eyes: Results After Obstruction of Schlemm's Canal. Arch Ophthalmol. 1971;86(1):65-71.

16. Toris CB, Koepsell SA, Yablonski ME, et al. Aqueous humor dynamics in ocular hypertensive patients. J Glaucoma. 2002;11:253-258

17. Toris CB, Yablonski ME, Wang YL, Camras CB. Aqueous humor dynamics in the aging human eye. Am J Ophthalmol. 1999;127(4):407-412.

18. Alvarado JA, Alvarado RG, Yeh RF, Franse-Carman L, Marcellino GR, Brownstein MJ. A new insight into the cellular regulation of aqueous outflow: how trabecular meshwork endothelial cells drive a mechanism that regulates the permeability of Schlemm's canal endothelial cells. Br J Ophthalmol. 2005;89(11):1500-1505. doi:10.1136/bjo.2005.081307

19. Johnson M, McLaren JW, Overby DR. Unconventional aqueous humor outflow: a review. Exp Eye Res. 2016;158:94-111. doi:10. 1016/j.exer.2016.01.017

20. Tamm ER. Functional morphology of the outflow pathways of aqueous humor and their changes in open angle glaucoma. Ophthalmologe. 2013;110(11):1026-1035. doi:10.1007/s00347-012-2670-4

21. Alvarado J, Murphy C, Juster R. Trabecular meshwork cellularity in primary open-angle glaucoma and nonglaucomatous normals. Ophthalmology. 1984;91(6):564-579. doi:10.1016/S0161-6420(84) 34248-8

22. Alvarado J, Murphy C, Polansky J, Juster R. Age-related changes in trabecular meshwork cellularity. Invest Ophthalmol Vis Sci. 1981;21 (5):714-727. 
23. Grierson I, Howes RC. Age-related depletion of the cell population in the human trabecular meshwork. Eye (Lond). 1987;1((Pt 2) (2)):204-210. doi:10.1038/eye.1987.38

24. Rohen JW, Lütjen-Drecoll E, Flügel C, Meyer M, Grierson I. Ultrastructure of the trabecular meshwork in untreated cases of Primary Open-Angle Glaucoma (POAG). Exp Eye Res. 1993;56:683-692. doi:10.1006/exer.1993.1085

25. Lütjen-Drecoll E, Shimizu T, Rohrbach M, Rohen JW. Quantitative analysis of 'plaque material' in the inner- and outer wall of Schlemm's canal in normal- and glaucomatous eyes. Exp Eye Res. 1986;42(5):443-455. doi:10.1016/0014-4835(86)90004-7

26. Wang K, Read AT, Sulchek T, Ethier CR. Trabecular meshwork stiffness in glaucoma. Exp Eye Res. 2017;158:3-12. doi:10.1016/j. exer.2016.07.011

27. Tripathi RC. Aqueous outflow pathway in normal and glaucomatous eyes. Br J Ophthalmol. 1972;56(3):157-174. doi:10.1136/bjo.56.3.157

28. Allingham RR, De Kater AW, Ethier CR, Anderson PJ, Hertzmark E, Epstein DL. The relationship between pore density and outflow facility in human eyes. Invest Ophthalmol Vis Sci. 1992;33(5):1661-1669.

29. Johnson M, Chan D, Read AT, Christensen C, Sit A, Ethier CR. The pore density in the inner wall endothelium of Schlemm's canal of glaucomatous eyes. Invest Ophthalmol Vis Sci. 2002;43 (9):2950-2955.

30. Acott TS, Westcott M, Passo MS, Van Buskirk EM. Trabecular meshwork glycosaminoglycans in human and cynomolgus monkey eye. Invest Ophthalmol Vis Sci. 1985;26(10):1320-1329.

31. McDonnell F, Dismuke WM, Overby DR, Stamer WD. Pharmacological regulation of outflow resistance distal to Schlemm's canal. Am J Physiol Cell Physiol. 2018;315(1):C44-C51. doi:10.1152/ajpcell.00024.2018

32. Johnstone MAM, Grant WMW. Pressure-dependent changes in structures of the aqueous outflow system of human and monkey eyes. Am J Ophthalmol. 1973;75(3):365-383. doi:10.1016/0002-9394(73)91145-8

33. Tripathi RC. Mechanism of the aqueous outflow across the trabecular wall of Schlemm's canal. Exp Eye Res. 1971;11(1):116-121. doi:10.1016/s0014-4835(71)80073-8

34. Tripathi RC. Ultrastructure of the trabecular wall of Schlemm's canal. (A study of normotensive and chronic simple glaucomatous eyes). Trans Ophthalmol Soc U K. 1970;89:449-465.

35. Hamanaka T, Bill A, Ichinohasama R, Ishida T. Aspects of the development of Schlemm's canal. Exp Eye Res. 1992;55 (3):479-488. doi:10.1016/0014-4835(92)90121-8

36. Krohn J. Expression of factor VIII-related antigen in human aqueous drainage channels. Acta Ophthalmol Scand. 1999;77(1):9-12. doi:10.1034/j.1600-0420.1999.770102.x

37. Garron LK, Feeney ML, Hogan MJ, McEwen WK. Electron microscopic studies of the human eye*. Am J Ophthalmol. 1958;46 (1):27-35. doi:10.1016/0002-9394(58)90031-X

38. Grierson I, Lee WR, Abraham S, Howes RC. Associations between the cells of the walls of Schlemm's canal. Albrecht Von Graefes Arch Klin Exp Ophthalmol. 1978;208(1-3):33-47. doi:10.1007/BF00406980

39. Grierson I, Lee WR. Junctions between the cells of the trabecular meshwork. Albrecht Von Graefes Arch Klin Exp Ophthalmol. 1974;192(2):89-104. doi:10.1007/BF00410696

40. Van Buskirk EM. Anatomic correlates of changing aqueous outflow facility in excised human eyes. Invest Ophthalmol Vis Sci. 1982;22 (5):625-632

41. Grierson I, Lee W. The fine structure of the trabecular meshwork at graded levels of intraocular pressure:(1) pressure effects within the near-physiological range $(8-30 \mathrm{mmHg})$. Exp Eye Res. 1975;20 (6):505-521. doi:10.1016/0014-4835(75)90218-3

42. Lee WR, Grierson I. Relationships between intraocular pressure and the morphology of the outflow apparatus. Trans Ophthalmol Soc UK. 1974;94:430-449.

43. Grierson I, Lee WR. Pressure-induced changes in the ultrastructure of the endothelium lining Schlemm's canal. Am J Ophthalmol. 1975;80:863-884.
44. Grierson I, Lee WR. Changes in the monkey outflow apparatus at graded levels of intraocular pressure: a qualitative analysis by light microscopy and scanning electron microscopy. Exp Eye Res. 1974;19(1):21-33

45. Dautriche CN, Tian Y, Xie Y, Sharfstein ST. A closer look at schlemm's canal cell physiology: implications for biomimetics. J Funct Biomater. 2015;6(3):963-985. doi:10.3390/jfb6030963

46. Grierson I, Lee W. The fine structure of the trabecular meshwork at graded levels of intraocular pressure:(2) pressures outside the physiological range (0 and $50 \mathrm{mmHg})$. Exp Eye Res. 1975;20 (6):523-530. doi:10.1016/0014-4835(75)90219-5

47. Grieshaber MCM, Pienaar A, Olivier J, et al. Clinical evaluation of the aqueous outflow system in primary open-angle glaucoma for canaloplasty. Invest Ophthalmol Vis Sci. 2010;51(3):1498-1504. doi:10.1167/iovs.09-4327

48. Dvorak-Theobald G. Schlemm's Canal: Its Anastomoses and Anatomic Relations. Trans Am Ophthalmol Soc. 1934;32:574-595.

49. Irshad FA, Mayfield MS, Zurakowski D, Ayyala RS. Variation in Schlemm's canal diameter and location by ultrasound biomicroscopy. Ophthalmology. 2010;117(5):916-920. doi:10.1016/j.ophtha.2009.09.041

50. Hann CRC, Vercnocke AAJ, Bentley MD, Jorgensen SM, Fautsch MP. Anatomic changes in Schlemm's canal and collector channels in normal and primary open-angle glaucoma eyes using low and high perfusion pressures. Invest Ophthalmol Vis Sci. 2014;55(9):5834-5841. doi:10.1167/iovs.14-14128

51. Battista SA, Lu Z, Hofmann S, Freddo T, Overby DR, Gong H. Reduction of the available area for aqueous humor outflow and increase in meshwork herniations into collector channels following acute IOP elevation in bovine eyes. Invest Ophthalmol Vis Sci. 2008;49(12):5346-5352. doi:10.1167/iovs.08-1707

52. Grieshaber MC, Pienaar A, Olivier J, Stegmann R. Channelography: imaging of the aqueous outflow pathway with flexible microcatheter and fluorescein in canaloplasty. Klin Monbl Augenheilkd. 2009;226 (4):245-248. doi:10.1055/s-0028-1109305

53. Saraswathy S, Tan JC, Yu F, et al. Aqueous angiography: real-time and physiologic aqueous humor outflow imaging. Vavvas DG, ed. PLoS One. 2016;11(1):e0147176. doi:10.1371/journal.pone.0147176

54. Doro D, Kotsafti O, Koerber N. Ultrasound biomicroscopy findings after canaloplasty. Klin Monbl. 2010;227(S 01):KV95.

55. Brusini P. Canaloplasty in open-angle glaucoma surgery: a four-year follow-up. Sci World J. 2014;2014:1-7. doi:10.1155/2014/469609

56. Garg A, Gazzard G. Selective laser trabeculoplasty: past, present, and future review-article. Eye (Basingstoke). 2018;32(5):863-876. doi: 10.1038 /eye. 2017.273

57. Grehn F, Klink T. Shallow Anterior Chamber. Glaucoma. Vol. 2. Chapter 75. Elsevier Limited; 2015.

58. Tetz M, Koerber N, Shingleton BJ, et al. Phacoemulsification and intraocular lens implantation before, during, or after canaloplasty in eyes with open-angle glaucoma. J Glaucoma. 2015;24(3):187-194. doi: 10.1097/IJG.0b013e318285ff13

59. Arthur SNS, Cantor LBL, WuDunn D, et al. Efficacy, safety, and survival rates of IOP-lowering effect of phacoemulsification alone or combined with canaloplasty in glaucoma patients. J Glaucoma. 2013;23(5):316-320. doi:10.1097/IJG.0b013e3182741ca9

60. Vizzeri G, Weinreb RN. Cataract surgery and glaucoma. Curr Opin Ophthalmol. 2010;21(1):20-24. doi:10.1097/ICU.0b013e328332f562

61. Lommatzsch C, Heinz C, Heiligenhaus A, Koch JM. Canaloplasty in patients with uveitic glaucoma: a pilot study. Graefes Arch Clin Exp Ophthalmol. 2016;254(7):1325-1330. doi:10.1007/s00417-016-3325-y

62. Kalin-Hajdu E, Hammamji K, Gagné S, Harasymowycz P. Outcome of viscodilation and tensioning of Schlemm's canal for uveitic glaucoma. Can J Ophthalmol. 2014;49(5):414-419. doi:10.1016/j. jcjo.2014.07.001

63. Iwao K, Inatani M, Seto T, et al. Long-term outcomes and prognostic factors for trabeculectomy with mitomycin $\mathrm{C}$ in eyes with uveitic glaucoma: a retrospective cohort study. J Glaucoma. 2014;23 (2):88-94. doi:10.1097/IJG.0b013e3182685167 
64. Papadaki TG, Zacharopoulos IP, Pasquale LR, Christen WB, Netland PA, Foster CS. Long-term results of ahmed glaucoma valve implantation for uveitic glaucoma. Am J Ophthalmol. 2007;144 (1):62-69. doi:10.1016/j.ajo.2007.03.013

65. Kaburaki T, Koshino T, Kawashima H, et al. Initial trabeculectomy with mitomycin $\mathrm{C}$ in eyes with uveitic glaucoma with inactive uveitis. Eye (Lond). 2009;23(7):1509-1517. doi:10.1038/eye.2009.117-cme

66. Brusini P, Tosoni C. Canaloplasty after failed trabeculectomy: a possible option. J Glaucoma. 2014;23(1):33-34. doi:10.1097/ IJG.0b013e318264cdbf

67. Körber N. Canaloplasty after trabeculectomy. Ophthalmologe. 2015;112(4):332-336. doi:10.1007/s00347-014-3162-5

68. Razeghinejad MR, Fudemberg SJ, Spaeth GL. The changing conceptual basis of trabeculectomy: a review of past and current surgical techniques. Surv Ophthalmol. 2012;57(1):1-25. doi:10.1016/j. survophthal.2011.07.005

69. Xin C, Chen X, Shi Y, Wang H, Wang N. Modified canaloplasty: a new, effective, and safe option for glaucoma patients with a disrupted schlemm canal wall. J Glaucoma. 2016;25(10):798-801. doi:10.1097/IJG.0000000000000420

70. Seuthe A-M, Ivanescu C, Leers S, Boden K, Januschowski K, Szurman P. Modified canaloplasty with suprachoroidal drainage versus conventional canaloplasty-1-year results. Graefes Arch Clin Exp Ophthalmol. 2016;254 (8):1591-1597. doi:10.1007/s00417-016-3370-6

71. Chiou AG, Mermoud A, Hédiguer SE, Schnyder CC, Faggioni R. Ultrasound biomicroscopy of eyes undergoing deep sclerectomy with collagen implant. Br J Ophthalmol. 1996;80(6):541. doi:10.1136/ BJO.80.6.541

72. Stegmann R, Pienaar A, Miller D, et al. Viscocanalostomy for open-angle glaucoma in black African patients. J Cataract Refract Surg. 1999;25 (March):316-322. doi:10.1016/S0886-3350(99)80078-9

73. Bellucci R, Morselli S. Reverse flap dissection for glaucoma surgery. Ophthalmic Surg Lasers Imaging. 2005;36(1):79-81.

74. Grieshaber MC, Schoetzau A, Flammer J, Orgül S. Postoperative microhyphema as a positive prognostic indicator in canaloplasty. Acta Ophthalmol (Copenh). 2013;91(2):151-156. doi:10.1111/ j.1755-3768.2011.02293.x

75. Beck AD, Lynch MG. 360 degrees trabeculotomy for primary congenital glaucoma. Arch Ophthalmol. 1995;113(9):1200-1202.

76. Scharioth G. From Deep Sclerectomy to Canaloplasty. Is It Possible to Re-Establish the Natural Outflow in Patients with Chronic OpenAngle Glaucoma? Szeged, Hungary: Department of Ophthalmology, Faculty of Medicine, University of Szeged, Szeged, Hungary; 2010. doi: $10.1017 / \mathrm{CBO} 9781107415324.004$

77. Kodomskoi L. 360-Kanaloplastik ohne iTrack mit und ohne ClearCornea-Phakoemulsifikation: frühe Ergebnisse. $\left[360^{\circ}\right.$ canaloplasty without iTrack with and without clear corneal phacoemulsification: early results]. Klin Monbl Augenheilkd. 2010. doi:10.1055/s-00301249546. German.

78. Scharioth GB. Risk of circumferential viscodilation in viscocanalostomy. $J$ Cataract Refract Surg. 2015;41(5):1122-1123. doi:10.1016/j. jcrs.2015.02.031
79. Haus A, Szurman P, Seuthe A-M. Catheter-independent suture probe canaloplasty with suprachoroidal drainage. Graefes Arch Clin Exp Ophthalmol. 2019;257(1):169-173. doi:10.1007/s00417-018-4182-7

80. Szurman P, Januschowski K, Boden KT, Szurman GB. A modified scleral dissection technique with suprachoroidal drainage for canaloplasty. Graefes Arch Clin Exp Ophthalmol. 2016;254 (2):351-354. doi:10.1007/s00417-015-3234-5

81. Seuthe AM, Januschowski K, Szurman P. Micro-invasive 360-degree suture trabeculotomy after successful canaloplasty - one year results. Graefes Arch Clin Exp Ophthalmol. 2016;254(1):155-159. doi:10.1007/s00417-015-3192-y

82. Scharioth GB. Canaloplasty re-establish the natural outflow in patients with chronic open-angle glaucoma. J Curr Glaucoma Pract. 2010;4(2):97-102. doi:10.5005/jp-journals-10008-1077

83. Vastardis I, Kontopoulou K, Fili S, Gatzioufas Z, Kohlhaas M. Comparison of performance between two microcatheter systems in ab externo canaloplasty: a retrospective comparison study. Eur J Ophthalmol. 2019;1120672119833547. doi:10.1177/1120672119833547

84. Kicińska A, Danielewska ME, Byszewska A, Lewczuk K RM: Safety and efficacy of three variants of canaloplasty with phacoemulsification to treat open-angle glaucoma: 6-month follow up. Poster presented at: 13th EGS Congress 2018, Florence, Italy, 19-22 May 2018

85. Byszewska A, Rudowicz J, Lewczuk K, Rękas M. Nowości w technikach chirurgicznych kanaloplastyki [Update on surgical techniques in Canaloplasty]. Okulistyka 2018;(march):1319. Polish.

86. Kicińska A, Danielewska ME, Byszewska A, Lewczuk K RM. Porównanie skuteczności i bezpieczeństwa trzech wariantów kanaloplastyki z jednoczesnym usunięciem zaćmy - obserwacje roczne [Comparison of efficacy and safety of three variants of canaloplasty with simultaneous cataract removal - annual observations]. Conference paper in: XI Międzynarodowe Sympozjum "Postępy w Diagnostyce i Terapii Schorzeń Rogówki" [XI International Symposium "Progress in the diagnosis and therapy of corneal diseases"], Cornea 2019; February 28 - March 2; 2019; Wisła, Poland. Polish.

87. Gallardo MJ, Supnet RA, Ahmed IIK. Viscodilation of Schlemm's canal for the reduction of IOP via an ab-interno approach. Clin Ophthalmol. 2018;12:2149-2155. doi:10.2147/OPTH.S177597

88. Grieshaber MC, Pienaar A, Stegmann R. Flap-sparing canaloplasty: a modified approach to Schlemm's canal. Graefes Arch Clin Exp Ophthalmol. 2019;257:1729-1732. doi:10.1007/s00417-019-04329-8

89. Klink T, Sauer J, Körber NJ, et al. Quality of life following glaucoma surgery: canaloplasty versus trabeculectomy. Clin Ophthalmol. 2015;9:7-16. doi:10.2147/OPTH.S72357

90. Brüggemann A, Despouy JT, Wegent A, et al. Intraindividual comparison of canaloplasty versus trabeculectomy with mitomycin $\mathrm{C}$ in a single-surgeon series. $J$ Glaucoma. 2013;22(7):577-583. doi:10.1097/IJG.0b013e318255bb30

91. Byszewska A, Rudowicz J, Lewczuk K, et al. Nowości w technikach chirurgicznych kanaloplastyki. [Update on Surgical Techniques in Canaloplasty]. Okulistyka: Kwartalnik Medyczny. 2016;3:14-19. Polish.
Clinical Ophthalmology

\section{Publish your work in this journal}

Clinical Ophthalmology is an international, peer-reviewed journal covering all subspecialties within ophthalmology. Key topics include: Optometry; Visual science; Pharmacology and drug therapy in eye diseases; Basic Sciences; Primary and Secondary eye care; Patient Safety and Quality of Care Improvements. This journal is indexed on PubMed
Central and CAS, and is the official journal of The Society of Clinical Ophthalmology (SCO). The manuscript management system is completely online and includes a very quick and fair peer-review system, which is all easy to use. Visit http://www.dovepress.com/ testimonials.php to read real quotes from published authors. 